\title{
Laboreal
}

Volume $13 \mathrm{~N}^{\circ} 1$ | 2017

Varia

\section{'Mudando para o time': a dimensão coletiva no trabalho de atletas de vôlei de praia}

'El cambio a favor del equipo': la dimensión colectiva en el trabajo de los atletas de voleibol de playa

'Changer pour l'équipe': la dimension collective dans le travail des athlètes du volleyball de plage

'Changing in favour of the team': the collective dimension in the work of beach volleyball athletes

\section{Louise Borba e Hélder Pordeus Muniz}

\section{(2) OpenEdition}

\section{Journals}

Edição electrónica

URL: http://journals.openedition.org/laboreal/780

DOI: $10.4000 /$ laboreal.780

ISSN: 1646-5237

\section{Editora}

Universidade do Porto

\section{Refêrencia eletrónica}

Louise Borba e Hélder Pordeus Muniz, « 'Mudando para o time': a dimensão coletiva no trabalho de atletas de vôlei de praia », Laboreal [Online], Volume 13 NN$^{0} 1$ | 2017, posto online no dia 01 julho 2017 consultado o 06 outubro 2019. URL : http://journals.openedition.org/laboreal/780 ; DOI : 10.4000/ laboreal.780

Este documento foi criado de forma automática no dia 6 outubro 2019

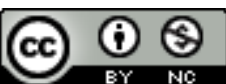

Laboreal está licenciado com uma Licença Creative Commons - Atribuição-NãoComercial 4.0 Internacional. 


\section{'Mudando para o time': a dimensão coletiva no trabalho de atletas de vôlei de praia}

'El cambio a favor del equipo': la dimensión colectiva en el trabajo de los atletas de voleibol de playa

'Changer pour l'équipe': la dimension collective dans le travail des athlètes du volleyball de plage

'Changing in favour of the team': the collective dimension in the work of beach volleyball athletes

Louise Borba e Hélder Pordeus Muniz

\section{NOTA DO EDITOR}

http://dx.doi.org/10.15667/laborealxiii0117b

Manuscrito recebido em : fevereiro/2017

Aceite após peritagem : abril/2017

\section{Introdução}

1 Neste artigo pretendemos apresentar uma breve discussão sobre a dimensão coletiva do trabalho, principalmente ao que se refere à necessidade de construção de referenciais cognitivos e valores comuns que possibilitem a comunicação e cooperação no desenvolvimento do/no trabalho. $O$ presente texto é parte dos estudos de uma pesquisa de doutoramento em curso, iniciada em setembro de 2014, pelo programa de PósGraduação em Estudos da Subjetividade do Instituto de Psicologia da Universidade Federal Fluminense, da cidade de Niterói, Rio de Janeiro, Brasil ; com colaboração de 
pesquisadoras do Atelier de Psicologia do Trabalho, da Faculdade de Psicologia e Ciências da Educação da Universidade do Porto, na cidade do Porto, Portugal.

2 Para nos auxiliar nesta discussão, apresentaremos como objeto de análise a dupla de jogadores de vôlei de praia, pois entendemos que, embora essa modalidade se apresente como um 'esporte coletivo', queremos apontar que para um coletivo realmente se afirmar é preciso que sejam considerados os saberes construídos pelos atletas em situações de treinos e jogos, e que se criem condições para que estes saberes circulem e se desenvolvam nesta atividade, mesmo quando a organização do trabalho no vôlei de praia exige uma alta rotatividade entre as duplas ou que seus componentes treinem em centros de treinamento diferentes.

O vôlei de praia teve sua origem nos EUA na década de 20, e mesmo já sendo praticado pela elite da zona litorânea da cidade do Rio de Janeiro desde a década de 50 , sua prática como esporte de alto rendimento [ $\left.{ }^{1}\right]$ no Brasil ganha projeção nas últimas duas décadas do século XX, principalmente quando o vôlei de praia se torna uma modalidade olímpica (Costa, 2005, 2007 ; Afonso \& Marchi Júnior, 2012).

4 Assim como o vôlei indoor ou de quadra, o objetivo no vôlei de praia é fazer com que a bola toque no chão da quadra adversária. De acordo com jogadores participantes da pesquisa, o jogo de vôlei (seja de quadra ou de praia) exige que eles desenvolvam os seguintes fundamentos : saque, recepção, bloqueio, levantamento e ataque ou virada de bola [2]. Entretanto, ao contrário do vôlei de quadra - que conta com uma equipe de 6 jogadores e mais 6 reservas de cada lado - o vôlei de praia tem duas condições que o caracterizam : as partidas se realizam ao ar livre e as equipes são compostas, somente, por uma dupla de jogadores de cada lado da quadra.

5 Estes são elementos extremamente importantes, e que terão nossa atenção neste artigo, principalmente quando damos destaque aos modos como uma dupla se configura, pois entendemos que é nela, e a partir dela, que os debates de normas desta atividade acontecem. Ao contrário dos atletas de vôlei indoor, que geralmente possuem contratos de trabalho firmados com clubes e associações desportivas especializadas, no vôlei de praia, assim como apontam alguns atletas, tudo se dá 'no amor e na palavra', ou seja, na realidade brasileira do vôlei de praia não existem contratos formais de trabalho, o que faz com que a maioria dos atletas seja responsável pelo gerenciamento da sua carreira, ficando a cargo deles não só a escolha de suas comissões técnicas, patrocinadores e locais para treinar, mas principalmente, a escolha de parceiros para jogarem os campeonatos nacionais.

6 A escolha de um parceiro, com quem seja possível 'montar um time' ou 'fazer um trabalho', envolve diversas variáveis técnicas, éticas, econômicas, políticas, com as quais os atletas têm de se deparar para formar uma dupla que seja capaz de buscar melhores resultados no ranking nacional e, consequentemente, suporte financeiro para continuarem na profissão de atleta. Além disso, a rotatividade e as mudanças de parceiros são quase uma constante: geralmente, parcerias com mais de um ou dois anos de existência são observadas nas duplas com as melhores posições no ranking e que, consequentemente, possuem melhores patrocínios e estrutura de treinamento.

7 Deste modo, ao darmos destaque para a dupla no vôlei de praia queremos debater como os jogadores conseguem cooperar e in(corpo)rar seus saberes, mesmo com o alto índice de troca de parceiros e/ou quando treinam separadamente. Acreditamos que essa discussão pode trazer subsídios importantes não só para os profissionais que trabalham 
com esse público específico (psicólogos, treinadores esportivos, etc.), mas implica, também, em como pensar modos de gestão dos coletivos de trabalho que levem em conta os debates e dramáticas da atividade.

\section{Um breve relato sobre o campo de pesquisa e o enquadre metodológico}

8 A primeira fase dessa pesquisa ocorreu entre agosto de 2015 e junho de 2016 com atletas profissionais autônomos de vôlei de praia em um centro de treinamento localizado na zona litorânea da cidade do Rio de Janeiro.

9 A partir da autorização dada pelos dois treinadores e pela psicóloga responsável pela equipe para visitarmos os treinos, nesta primeira fase concordaram em participar de nossa pesquisa 5 (cinco) atletas : 2 (dois) do sexo feminino, parceiras de dupla e 3 (três) do sexo masculino, sendo dois deles parceiros de dupla.

10 Para nos auxiliar nas visitas a este campo partimos das afirmações de Dias (2008) que aponta que o uso de materiais de audiovisual (como filmes e documentários) e relatos e biografias podem tornar-se informantes preciosos e uma fonte interessante para entendermos a história da prática esportiva, visto que a partir desses relatos e de uma leitura mais atenta, é possível visualizar '(...) as motivações, os valores, as aspirações e frustrações em torno desses esportes, bem como seu cotidiano' (Dias, 2008, p. 7). Portanto, de modo a entender o nosso terreno e nos subsidiar com informações referentes ao vôlei de praia, inclusive nos auxiliando durante as observações aos treinos e na condução das entrevistas, acompanhamos o programa 'Roda de Vôlei', transmitido pelo canal brasileiro de televisão a cabo Bandsports. Este programa é apresentado por ex-atletas e conta, geralmente, com a presença de um convidado, que pode ser um atleta ou ex-atleta do vôlei de praia ou de quadra, ou um treinador da modalidade, apresentando sua experiência enquanto profissional.

11 Outros materiais de audiovisual também foram importantes, como o documentário 'A praia em Atlanta', realizado pela produtora 'Quebra Eixo' e exibido pelo canal ESPN, que conta a trajetória das duas duplas brasileiras femininas de voleibol de praia na estreia da modalidade nos jogos olímpicos de Atlanta em 1996, e alguns episódios da série 'A vaga', de produção do canal HBO, que acompanhava atletas de diversas modalidades, dentre elas o vôlei de praia, em busca da vaga para participar dos Jogos olímpicos de 2016 na cidade do Rio de Janeiro. Essa série mostrava em cada episódio aspectos relacionados ao fazer esportivo e à busca do objetivo de disputar as olimpíadas, dando destaque aos episódios sobre a saúde dos atletas e a relação deles com seus técnicos e o treinamento.

Durante nosso período em campo, foram feitas observações dos treinos com bola e 6 (seis) entrevistas, sendo duas restituições/devoluções de entrevista ; uma observação de estudo de vídeo de jogo e observação de jogos. Essas atividades aconteceram da seguinte maneira :

- Observação dos treinos com bola : onde são trabalhados os fundamentos básicos do vôlei de praia : saque, recepção, levantamento e virada de bola de acordo com a necessidade de cada dupla e o calendário das competições. Aconteciam das $8: 00$ às $11: 00$. A pesquisadora anotava a hora, a dupla que estava em quadra, as condições climáticas e os conteúdos do treino. Durante o treino eram observadas as orientações dos treinadores aos atletas e o 
modo como a dupla se organizava para cumprir os objetivos do treino. Em algumas ocasiões, após o término do treino, a pesquisadora tirava dúvidas relativas a algumas situações observadas com os atletas - individualmente e/ou em dupla - e com os treinadores (falas, reações do grupo frente a uma jogada, etc.).

- Entrevistas : Foram realizadas 4 (quatro) entrevistas iniciais após os treinos técnicos, na praia. Entrevista semiaberta, onde foram abordados os seguintes tópicos: escolha pela modalidade vôlei de praia, a iniciação no esporte e a partir de que momento a prática esportiva se torna profissão. A partir desses elementos, a pesquisadora buscava entender as relações dos atletas com esta atividade.

- Restituições/devoluções de entrevista (2) : As restituições foram feitas com dois atletas (um do sexo masculino e uma do sexo feminino) de acordo com a disponibilidade de horário deles. Nessas restituições foram entregues cópias da transcrição da primeira entrevista, e debatidas com os atletas algumas falas que suscitaram dúvidas na pesquisadora ou tópicos que foram discutidos em grupo de pesquisa e que poderiam ser material de reflexão acerca de sua atividade de trabalho. Durante o período de contato com o campo, o centro de treinamento foi desfeito e as duplas se separaram, e por isso uma das restituições foi feita fora do centro de treinamento, quase um ano depois da primeira entrevista.

- Observação de estudo de vídeo de jogo : Realizada após o treino técnico na residência do treinador. Observação de duas partidas gravadas em vídeo. Observação da dinâmica de estudo da dupla quanto ao seu posicionamento em quadra, relação com o parceiro, relação com os adversários. Observação de posturas e gestos.

- Observação de jogos : Assistimos a algumas competições transmitidas, em sua maioria, ao vivo pela internet ou pela televisão - visto que muitos jogos ocorrem em diversas regiões do país - e a dois jogos presencialmente.

13 A partir das análises das entrevistas e das observações feitas no campo, delimitamos a dupla de jogadores como ponto principal dos debates, onde a partir dela, vários tópicos se desdobram como a gestão da saúde no trabalho, formação profissional, a gestão do coletivo, entre outros.

\section{0 trabalho no esporte como atividade: o corpo-si (em) no jogo}

Deixar de ser jogador para ser atleta é outra coisa... (Corina, nome fictício, atleta, 30 anos)

15 A fala desta atleta se deu no momento em que ela nos contava sobre o seu dia a dia de trabalho e o quanto estava sendo difícil para ela, naquele momento, afirmar-se nesta escolha profissional. Essa fala para nós é importante pois marca o quanto há de engajamento nessa atividade, uma vez que, para estes atletas, há muito mais no/em jogo do que apenas a execução de técnicas de movimentos ou cumprimento de regras.

Portanto, para falarmos desse engajamento queremos frisar aqui nosso conceito base para discutirmos a dimensão coletiva do trabalho, que é o conceito de atividade. Embora a palavra atividade no esporte seja muito utilizada - e esta esteja inserida no conjunto de práticas de 'atividade física', aqui no sentido de pôr o corpo, o físico, em movimento - queremos ampliá-la e considerá-la, também, como aquilo que, embora tenha uma dimensão que é da regra, do protocolo, do técnico, também é composto de 
uma dimensão invisível, mas vital, do fazer humano (Schwartz \& Durrive, 2007/2010 ; Durrive, 2011).

17 O conceito de atividade é altamente complexo e, certamente, merece uma discussão mais aprofundada, porém neste artigo faremos uso - por ora, e não menos abrangente da noção que Schwartz $(2014,2015)$ nos apresenta da atividade como um 'encaixamento de debates de normas' imerso num mundo de valores, o que torna o 'trabalhar' sempre uma dramática de usos do corpo-si. o que Schwartz nos aponta com essas afirmações é que, quando trabalhamos, nosso fazer é sempre marcado por uma dimensão das normas (sociais, econômicas, relacionais, políticas, etc.), de regulamentos, de protocolos e procedimentos técnicos. Mas, ao mesmo tempo, nosso fazer também apresenta uma dimensão que é singular, presente no modo como cada um de nós se apropria dessas normas e in(corpo)ra esse debate com os valores que circulam na situação de trabalho, produzindo novas normas na tentativa de viver em saúde.

Ainda segundo Schwartz (2014), o encontro dessas duas dimensões nos afeta sempre como uma dramática, no sentido em que quando trabalhamos, somos convocados a todo momento a fazer escolhas que envolvem não só recursos pessoais, de nossa história de vida, mas também recursos que se dão na nossa relação com os outros e com o mundo. O suporte dessas dramáticas é o que Schwartz vai chamar de corpo-si, onde não há uma supremacia do corpo, domínio do saber médico, nem da 'alma', do 'emocional', mas um corpo-si que é uma '(...) entidade (...) que transgride todas as fronteiras entre o biológico e o histórico (...)' (Schwartz, 2014, p. 264), onde acontece a ancoragem entre o registro 1 (do protocolo) e o registro 2 (singular) da atividade, e nele é possível a reconfiguração de novas normas de viver.

Portanto, nessa discussão, quando nos referimos ao corpo do atleta, partimos desta perspectiva de que não há uma separação 'emocional-físico'; 'técnico-pedagógico'; 'intelectual-manual', mas que todas essas dimensões se dão em processo dinâmico no corpo-si. Acrescentamos ainda, e principalmente no que se refere ao foco deste artigo, que esse corpo-si e todas as dramáticas que ele suporta, nunca acontecem de modo apartado da situação e do coletivo em que ele se encontra.

Desse modo acreditamos ser importante esclarecer, também, sobre que coletivo estamos a falar. Assim como a palavra atividade, a palavra coletivo também se dá muito associada à prática esportiva, principalmente ligada à noção de que não há somente um praticante, mas uma equipe onde as funções são compartilhadas por mais de um atleta. Essa é uma noção que para nós se apresenta como limitada e estanque, pois para analisar de fato um coletivo é necessário entendê-lo como um processo dinâmico que se constitui a partir das situações reais de trabalho, onde os trabalhadores têm a possibilidade de construir projetos em comum e onde é considerado o encontro de escolhas e valores, de dramáticas de usos do corpo-si que estão em jogo (e no jogo). Para isso é preciso colocar em sinergia toda uma multiplicidade de 'agir competentes' (Schwartz,1998; Schwartz \& Durrive, 2007/2010), individuais e coletivos, não só para alcançar objetivos que foram construídos em comum, mas para criar um espaço em que seja possível desenvolver novos modos de 'agir em competência'.

\subsection{0 jogo e a perform(atividade)}

Como apontamos na introdução deste texto, uma partida de vôlei de praia se desenvolve pela execução dos fundamentos de saque, recepção, levantamento, bloqueio 
e virada de bola. Para cada fundamento desse existem técnicas de movimentos, posturas e posicionamentos específicos, ou como os jogadores entrevistados chamam : 'movimento padrão'. Segundo eles, a busca pela execução 'quase perfeita' desses movimentos é essencial, pois é isso que vai possibilitar a dinamização e a (re)criação das jogadas. Segundo Gonçalo (atleta, nome fictício, 26 anos), as melhores duplas de vôlei de praia brasileiras são aquelas que conseguem executar com eficácia $100 \%$ dos movimentos padrão e, por isso mesmo, são as duplas que mais 'reinventam' as jogadas de acordo com as situações do jogo (condição de vento, modo como a bola chega para o jogador, dinâmica com a dupla adversária, etc.).

Uma situação, por exemplo, que é muito comumente trazida pelos atletas é a dificuldade de se fazer um levantamento de bola por 'toque acima da cabeça' (quando se utilizam as duas mãos, buscando o domínio da bola com a ponta dos dedos). Durante o acompanhamento de alguns treinos, observamos que na praia, devido à areia e ao suor, a chance de a bola escorregar e o levantamento com toque sair errado é muito grande, correndo o risco de eles levarem uma falta por 'dois toques' durante o jogo [ $\left.{ }^{3}\right]$. Entretanto, realizar o levantamento da bola com um toque acima da cabeça aumenta a diversidade de possibilidades de lançar a bola para a quadra adversária e conseguir a pontuação. Portanto, muitos atletas, por não possuírem o movimento de toque bem desenvolvido, acabam não se arriscando durante uma partida e preferem fazer o levantamento por 'manchete' (utilizando uma base de domínio para a bola com os punhos cruzados e braços esticados à frente do corpo), o que torna o ataque mais previsível para a defesa da dupla adversária.

Ao descrevermos essa situação e tomarmos como base para sua análise as perspectivas teóricas que discutimos anteriormente, entendemos que uma partida de vôlei de praia nunca é somente a aplicação de jogadas e a execução perfeita dos fundamentos de saque, recepção, ataque e defesa. É claro que o estudo dos adversários e a preparação antes de uma partida é muito importante, mas a cada jogo, a cada levantamento de bola, a cada movimentação em quadra, não podemos desconsiderar que sempre há algo de inédito que se configura, fazendo com que os atletas se deparem o tempo todo com eles mesmos e com as normas e regras da modalidade para dar conta das inúmeras situações e variabilidades durante a partida.

Deste modo, acreditamos que a partida de vôlei de praia se dá como uma 'perform(atividade)' de um diálogo entre os companheiros de dupla (de modo colaborativo), com a dupla adversária (de modo competitivo), com as condições do meio (climáticas, vento, público) e com os regulamentos da modalidade, onde são colocados em jogo (e no jogo) diversos debates de normas e renormatizações. Em um dos encontros com os atletas, tivemos a oportunidade de presenciar um estudo de vídeo de duas partidas : uma da dupla pesquisada e outra da dupla adversária, que até o ano de 2016 era considerada pela Federação Internacional de Voleibol (FIVB) uma das melhores duplas de vôlei de praia do mundo. 0 estudo foi feito na residência do técnico, com a presença dos dois atletas e do preparador físico. Antes de começarem a ver o vídeo, cada atleta pegou um caderno onde constavam os nomes de todos os jogadores do campeonato. Nesse caderno eram anotadas as características de cada jogador e todas as possíveis jogadas (já estudadas anteriormente). Ao começar o vídeo da dupla adversária a ser estudada, mais do que o posicionamento e a movimentação de quadra, o técnico me explica que eles querem ver como os atletas 'conversam' entre si, produzindo um diálogo (gestual, verbal) entre eles e que indicam as possibilidades de 
jogadas. Portanto, nos chamou a atenção uma das falas do técnico apontando aos atletas que percebessem 'o olhar' do adversário para seu companheiro e a postura corporal antes do movimento de ataque.

A descrição dessa situação observada por nós aponta para algo que precisa ser construído na dupla e que vai para além do encontro de competências técnicas. A princípio, as questões técnicas ou valências [4] esportivas que cada atleta possui podem ter um peso maior na busca de um parceiro. Por exemplo, se um atleta, na sua história profissional e de acordo com sua composição corporal, desenvolveu mais competências de força de ataque, é possível que ele busque um parceiro que possua 'volume de jogo', ou seja, um outro atleta que tenha valências nos fundamentos de defesa, como recepção e levantamento de bola. Ou, se por acaso, o atleta tiver uma composição corporal específica que favoreça determinada movimentação em quadra, tal como uma altura favorável ao bloqueio, ele tende a procurar um parceiro que seja mais 'leve' e que por isso tenha melhor movimentação de defesa de fundo de quadra.

Logo, o encontro de uma dupla nunca se dá a partir de uma 'tábula rasa', ou seja, para que se criem condições de formação de uma dupla é preciso que já exista um saber construído por parte de cada atleta. Ao mesmo tempo, para que a dupla se transforme em um 'time' é preciso que se criem condições para que haja cooperação entre os atletas, onde seja possível um espaço de negociação entre eles de modo que a dupla consiga construir um referencial cognitivo comum.

Alguns autores das chamadas Clínicas do trabalho [5] nos trazem alguns componentes para nos auxiliar a pensar essa dimensão do coletivo na dupla de atletas de vôlei de praia. Figueiredo e Athayde (2005) apontam que a existência de um cognitivo compartilhado entre os pares sobre o fazer pode ser um requisito importante para que se dê uma cooperação considerada eficiente, onde é possível que os trabalhadores consigam suprir as falhas e lacunas de cada um a partir do suporte mobilizado no coletivo. Quando um coletivo se forma, circulam ali regras dinâmicas que ajudam a organizar e proteger esse coletivo. Portanto, pressupomos que na formação de uma dupla, o compartilhamento de saberes e regras da atividade já consolidadas estão presentes no critério de escolha, e somente elas serão capazes de subsidiar o trabalho para superar as variabilidades das situações.

28 Um outro autor que nos auxilia a pensar nesta questão é Clot $(2007,2010)$ e o conceito de 'gênero profissional', onde ele aponta que o trabalhador se utiliza de um patrimônio histórico da sua atividade em seu meio de ação. Esse patrimônio não está relacionado somente ao uso de técnicas, mas se refere a toda uma memória social e a um discurso 'estocados' na atividade e que estão sempre prontos a serem mobilizados nas situações de trabalho. Assim, antes dos jogadores se conhecerem e formarem uma dupla, eles já têm algo em comum que é o gênero profissional, que permite que eles tenham um repertório de fundamentos, de técnicas, de modos de se comunicar com os colegas que torna possível que pessoas que não se conheçam possam começar a conversar e a entender o que ambos estão falando. Porém, esse gênero está sempre se transformando pela estilização de cada jogador ou dupla. Assim, é necessário construir a relação para que esse trabalho com e sobre o gênero se efetue.

29 A fala de um dos atletas participantes desta pesquisa, Breno (nome fictício, 30 anos), pode nos ajudar a pensar como esse patrimônio funciona e como ele se configura mesmo quando os jogadores treinam em regiões diferentes do país : 
(...) o vôlei de praia, infelizmente, tem muito isso : muita troca de dupla. E aí você tem que se adaptar o mais rápido possível com o seu parceiro. Eu lembro que teve um parceiro, que eu jogava a etapa com ele, que a gente não tinha nem treinado junto (...). E eu jogava bloqueando, e eu lembro que ele também jogava bloqueando. E ele gostava de jogar do lado que eu gostava. Então a gente falou 'opa, então, vamos organizar aqui, você bloqueia melhor do que eu, então você vai mais para o bloqueio. Eu fico no fundo, eu jogo melhor do que você na posição contrária, então eu vou para posição contrária'. E aí a gente se acertou e acabou que deu muito certo. (...) ele ia me ensinando, dando os toques na defesa. Eu era muito, muito cru na defesa. Eu ficava muito ansioso para tentar defender tudo, e não defendia nada. Ele falou : 'Oh, você vai defender essa bola e essa bola. Eu vou bloquear essa bola e essa bola'. Então a gente comunicando, a gente conseguiu se ajustar ali, e pô, e deu muito certo. (...) eu lembro que eu ligava para ele e falava : 'e aí ? Como estão os treinos ?'. Aí ele falava : 'Estão bons, vou trabalhar essa bolinha, a bola mais acelerada para você'. $\mathrm{E}$ aí ele também levantava muito bem. Então a gente foi se adaptando. Então eu treinava, eu lembro que eu chegava, treinava a bola acelerada para ele. Eu tive que mudar de posição, e aí eu fui para saída (de bola), e aí só treinando acelerada para ele, acelerada para ele. E o passe que ele gostava era um passe mais alto, e eu tinha um passe mais baixo, então eu tive que aumentar o meu passe. (Breno, atleta, 30 anos)

Portanto, ao considerarmos a partida de vôlei de praia como 'perform(atividade)', queremos frisar que mesmo que as duplas de vôlei de praia treinem separadamente, existe um patrimônio da atividade (re)construído pelos atletas e mobilizado na medida em que uma dupla é formada. A partir da fala do atleta, podemos perceber que para que eles pudessem jogar juntos, além da necessidade de um saber pré-desenvolvido de ambos, foi necessário criar uma condição em que eles pudessem compartilhar esses saberes e produzir novos ajustes e modos de jogar juntos. Desse modo, a comunicação e o compartilhamento de uma linguagem (falada, gestual) são fundamentais para a construção e atualização de um coletivo, pois além dos termos técnicos e táticos referentes ao vôlei de praia, é preciso entender o que é uma 'bola acelerada', por exemplo.

31 Lembramos de outra situação, durante uma de nossas visitas aos treinos, em que o treinador orienta uma das atletas para que ao fazer o fundamento de recepção, ela deveria 'subir a bola'. A atleta questionou essa expressão, pois não entendia o que significava fazer 'subir a bola'. O treinador então explica que ela deveria fazer um movimento e uma postura de braços e pernas que possibilitassem a bola subir, o que facilitaria que a parceira realizasse o fundamento de levantamento de maneira mais eficiente, o que aumentaria as possibilidades da parceira de realizar um posterior ataque à quadra adversária.

Estar presente no campo e entender essas questões da atividade é importante, pois só assim saímos da armadilha de considerar as questões 'emocionais' e 'relacionais' como algo que se dá apartado das situações de trabalho. Como discutimos anteriormente, a construção de um coletivo no esporte não está dada e, portanto, deve-se estar atento às ações e intervenções sobre ele.

33 Desconsiderar a situação de trabalho e o modo como os atletas fazem uso dos saberes (não só os formais técnicos, mas aqueles desenvolvidos em meio à ação em treinos $\mathrm{e}$ jogos) é o que Schwartz (2014, p. 270) nos aponta como uma problemática, no sentido de que pode acarretar em '(...) uma restrição indevida da atividade, uma negação das 
dramáticas, uma desconexão de suas sinergias esforço de saber/esforço de viver, para pôr em lugar disso um saber produzido às cegas'. Ou seja, quando não se criam espaços efetivos de negociação, de comunicação e de real cooperação entre os atletas, onde eles possam se apropriar das regras e saberes do vôlei de praia (renormatizações) para o coletivo-dupla que se forma, pode haver uma interrupção daquilo que chamamos de perform(atividade). E nesse sentido, para que não haja adoecimento, é preciso estar atento para que os atletas/duplas busquem um novo posicionamento, ou como Schwartz aponta, um novo recentramento perante os diversos constrangimentos e impedimentos da atividade.

\section{0 coletivo e a cooperação 'apesar de' : compartilhar saberes e valores}

Ao pensarmos nessa discussão, lembramos da fala da atleta Corina quando ela nos conta sobre uma situação de jogo em que um dos componentes da dupla se encontra em dificuldade. Nessa fala, podemos entender como os diversos debates acontecem e como essas dramáticas do corpo-si se colocam a partir da mobilização de saberes e da construção de uma confiança que possibilite a parceira voltar a 'jogar junto' :

[O vôlei de praia] é um esporte coletivo de dupla, mas é um esporte totalmente individual, porque você tem que estar o tempo todo centrada no seu. A partir do momento que você sai do seu para cobrir, olhar da sua parceira, tá errado porque você não consegue fazer nem o dela e nem o seu (...). Sua parceira está horrorosa hoje, você fica : 'putz, o que posso fazer para trazer essa menina ?'. Difícil chamar uma atenção, 'vambora !'. Se a pessoa não tiver bem ela não vai... é muito difícil. Aí eu vou mudar minha postura aqui e ela vai vir comigo (...), você pode ir para o saque começar a jogar pra caramba, fazer ace [ponto de saque], fazer defesa, virar bola, e 'vem comigo parceira ! '. Daqui a pouco você vai contagiando ela (...) porque é difícil você motivar, mas com as suas ações, assim efetivas, você consegue desafogar um pouco a pessoa e ela daqui a pouco fala 'po vambora !' (...) pegar um pouco aí da sua energia, e ir para cima, porque é difícil. Você não está no corpo dela, você está no seu corpo e você tem controle sobre o seu. (...) você pode passar informações, (...) só que se ela não estiver tranquila, não estiver confiante ela não vai fazer. E assim estamos todos na mesma barca afundando. Se você se entregar (...) ou começar a 'vender' a parceira, porque isso acontece demais, tipo,'olha ! Ela é um lixo, tá vendo ? Tá todo mundo vendo. Ela é um lixo, não sou eu que estou errando'. Só que o time vai perder. Isso acontecia no meu extime. Então acho que a menina [para] ajudar, é mudando o seu, mudando para o time. (Corina, atleta, 30 anos)

35 A partir dessa fala, mesmo que a atleta tenha apontado que o vôlei de praia ao mesmo tempo que é coletivo 'é totalmente individual', entendemos, assim como aponta Schwartz ao citar o ergonomista Bernard Pélegrin (Schwartz, 2014) que esse 'individual' também é composto de uma dimensão coletiva na medida em que, na situação de jogo, é possível integrar e ajustar a necessidade (individual) ao conjunto produzido no/para o time, ou seja, assim como Corina nos fala, a partir do momento que ela tem que fazer também as funções de sua parceira, além das suas próprias, o coletivo se desfaz, pois para ajudar é preciso 'mudar o seu, mudando para o time'. para essa discussão ao fazerem uma análise da atividade coletiva no esporte. Ao 
conceberem a análise da atividade e das situações complexas sem perder de vista o modo como as ações acontecem e como os atletas se apropriam dos diversos objetivos e metas que ocorrem durante o desenrolar de uma partida de rúgbi, eles afirmam que a atividade coletiva existe quando as ações individuais e seus objetivos estão subordinados a uma ação ou objetivo em comum, objetivo este que foi transformado por esse coletivo. Desse modo eles apontam que restringir uma análise do coletivo tendo somente como objeto o que cada atleta deve fazer no time (como uma repartição de tarefas) não dá conta dos comportamentos ou performance produzidos. É preciso levar em conta o modo como as referências cognitivas de cada atleta se compõem (referencial cognitivo comum) e são colocadas em situação determinando os encaminhamentos e procedimentos para as resoluções de problemas. Segundo os autores, é a partir do modo como os atletas compõem essa atividade coletiva que é possível organizar o suporte para as iniciativas individuais (Bouthier, 1989).

Em meio a essa discussão, portanto, não podemos perder de vista que para além do compartilhamento/composição de referenciais cognitivos, para que uma atividade coletiva aconteça é preciso compartilhar de uma dimensão ética e de valores em comum. Embora a atleta tenha tomado a decisão de motivar a colega através de uma exacerbação de sua performance como atleta e, na medida em que se empenha e busca mobilizar a parceira de um modo mais efetivo do que se usasse uma comunicação verbal para o estímulo, essa decisão só é possível na medida em que, mesmo que se esbarre em algum limite real da parceira, naquela dupla houve a possibilidade de compartilhar um dimensionamento do valor solidariedade e cooperação expresso na tentativa de 'ganhar junto' e, se não conseguir, 'afundar junto'.

Neste sentido, existe um reconhecimento do outro enquanto par, o que torna possível o engajamento necessário de uma das atletas na tentativa de responder à situação vivenciada. Quando esse suporte e esse reconhecimento não acontecem, a atividade individual é 'vendida' como nos aponta a atleta, e a fragilidade do parceiro é exposta. Desse modo, a partilha de valores e de uma ética profissional é fundamental para a construção de uma confiança no agir de um par, pois a singularidade só é possível na medida em que há um coletivo que permita que ela se manifeste.

Entretanto, não podemos ignorar a relação de competitividade como um dos motes da organização do trabalho no vôlei de praia, assim como na prática esportiva de alto rendimento em geral. E assim nos perguntamos: como os atletas se relacionam com essa questão ? Como compartilhar saberes e valores mesmo correndo o risco de que o atual parceiro pode vir a ser seu adversário no futuro?

40 A partir de nossas visitas ao campo observamos que dentro do circuito nacional as duplas se conhecem bastante, não só porque elas se enfrentam constantemente e os atletas têm acesso aos vídeos dos jogos, mas também porque em alguns casos atletas adversários e, até mesmo, duplas adversárias treinam no mesmo centro de treinamento e, às vezes, têm o mesmo treinador. Em uma de nossas visitas aos treinos na praia, uma das atletas do centro de treinamento estava com uma lesão na tíbia que não a impossibilitava de jogar, mas restringia sua movimentação em quadra. Uma outra atleta, que treinava no mesmo centro de treinamento, mas que compunha uma outra dupla, disse que isso seria um fator estratégico caso elas se enfrentassem durante a próxima etapa do circuito : ao forçarem o saque na atleta lesionada, a obrigariam a fazer uma movimentação não tão eficiente, desencadeando uma recepção frágil e, consequentemente, um levantamento e um posterior ataque menos eficaz. 
Imaginarmos esse tipo de ação em um outro espaço profissional poderia ser considerado desleal - embora algumas práticas de 'gerenciamento de pessoas' promovam ações 'disfarçadas' que mobilizam alguns comportamentos similares nos seus trabalhadores - mas dentro dessa organização, o atleta de vôlei de praia aprende a jogar com as fragilidades do adversário, como pudemos observar em uma partida do campeonato nacional. A dupla participante da nossa pesquisa, na época ocupando o $8^{\circ}$ lugar no ranking, disputava o primeiro lugar de uma etapa do circuito nacional com a dupla que estava no $1^{\circ}$ lugar. Embora tenham perdido a partida, eles conseguiram tornar a disputa difícil para a dupla adversária, pois ao forçarem o saque no atleta mais alto e pesado, o obrigavam a se deslocar mais para alcançar a rede e realizar um bloqueio eficiente. Somado ao calor e à alta temperatura da quadra de areia, o atleta ficava muito cansado, o que facilitava o ataque da dupla participante de nossa pesquisa.

Neste sentido, existe uma ética profissional onde é possível ganhar do adversário não só dentro das regras do jogo e regulamentos da confederação [6], mas a partir das condições em que a dupla adversária se apresenta. Desde que seja possível jogar com o colega de dupla construindo um jogo onde ninguém se sobrecarregue e ninguém sinta que está sendo usado pelo outro, a dinâmica com o adversário também vai determinar a mobilização de saberes e a estratégia da dupla durante uma partida.

Ainda sobre a organização gerencial desse esporte, destacamos que além da pontuação no ranking que cada dupla vai adquirindo com suas vitórias, existe o ranking de pontos de cada atleta. Ou seja, um parceiro da dupla pode ser mais bem avaliado nacionalmente que o outro, o que segundo o atleta Breno pode trazer prejuízos na hora de formar um time, visto que, a qualquer momento, um outro atleta do circuito pode vir e 'tirar seu parceiro'. Outro atleta participante de nossa pesquisa, Bernardo (nome fictício, 28 anos), nos conta sobre a dificuldade que estava a ter na escolha de seu novo parceiro, pois, por mais que ele analisasse quais competências esportivas que um novo parceiro poderia ter, ele não tinha à sua disponibilidade quem ele gostaria, pois sabia que os atletas mais bem ranqueados, inclusive com pontuação de mundial, não aceitariam jogar com ele e correr o risco de ter uma queda de pontuação.

Essa dinâmica de que ao mesmo tempo que tem que cooperar com a dupla, tem de se ver com a avaliação individual de seu rendimento, está presente como uma das características de estratégias gerenciais contemporâneas que buscam individualizar as formas de avaliação mesmo em situações de trabalho onde a importância da dimensão coletiva para a eficácia é evidente. Além disso, como o critério de avaliação nesse meio acaba por ficar restrito a uma performance e ao desempenho em quadra, o modo como o trabalho dos atletas acontece e como eles fazem a gestão da sua atividade acaba por ficar na penumbra da noção de 'talento' ou 'dom'. Ou seja, o tratamento dos saberes produzidos nesta atividade é estanque, fragmentando ainda mais a construção de um coletivo, na medida em que se separam 'vencedores' de 'perdedores'.

\section{Conclusão}

No presente artigo, escolhemos focar nossa análise na formação das duplas de atletas de vôlei de praia de modo a destacar a complexidade desse trabalho, que envolve um corpo-si que traz a história da profissão e a normatividade social, a dimensão vital de normatividade de um vivente e, por fim, o uso de si por si dos atletas e o desafio de combinar esses usos num projeto coletivo de trabalhar/jogar juntos. Esse viver em 
comum envolve o compartilhamento e a construção de saberes e técnicas, mas também o trabalho com os valores que são dimensionados em normas que regulam não apenas a partida, mas a parceria entre os atletas.

Nesse sentido, foi importante interrogarmos o vôlei de praia como atividade de trabalho profissional que está sujeita a constrangimentos e a pressões de determinadas formas de gerenciamento que podem dificultar ou favorecer o desenvolvimento dos atletas de forma individual e coletiva no esporte. Analisar as condições de trabalho e a forma como este trabalho é gerenciado auxilia a entender as dificuldades ou possibilidades enfrentadas por esses atletas e pode ser um passo importante para compreender as estratégias e escolhas presentes em sua atividade.

Deste modo, nossas visitas a treinos e jogos têm sido fundamentais para acompanhar e escutar de alguns atletas o que está para além das 'quatro linhas', e tentar entender as dramáticas e debates com as quais eles se deparam para construir um time, mesmo quando o gerenciamento do esporte dificulta o desenvolvimento das duplas, na medida que afirma valores que não são os da cooperação e da solidariedade, mas um estímulo a uma individualização das carreiras, fazendo com que cada jogador seja também um empresário de si mesmo.

Como se trata de uma pesquisa em curso, o desdobramento deste artigo envolve o retorno ao campo de modo a apresentar e debater, com os atletas e os profissionais que os assessoram (treinadores, fisioterapeutas, psicólogas, etc.), as questões que foram trabalhadas até agora. Pretendemos com isso produzir condições para que tanto possam ser discutidos possíveis encaminhamentos desses profissionais para a sua profissão, como possam ser construídos novos problemas a serem mais bem trabalhados nessa colaboração entre pesquisadores e profissionais que visa contribuir com a reflexão sobre como vem se dando o processo de formação e desenvolvimento profissional.

\section{BIBLIOGRAFIA}

Afonso, G. F., \& Marchi Júnior, W. (2012). Como pensar o voleibol de praia sociologicamente. Motriz : Revista de Educação Física, 18(1), 72-83. Retirado em fevereiro, 14, 2017. https://dx.doi.org/ 10.1590/S1980-65742012000100008

Bouthier, D., \& Savoyant, A. (1984). A contribution to the learning of a collective action: The counter-attack in rugby. International Journal of Sport Psychology, 15, 1, 25-34.

Bouthier, D. (1989). Les conditions cognitives de la formation d'actions sportives collectives. Le Travail Humain, 175-182.

Clot, Y. (2007). A função psicológica do trabalho. $2^{a}$ edição - Petrópolis, RJ : Vozes.

Clot, Y. (2010). Trabalho e poder de agir. Belo Horizonte : Fabrefactum.

Confederação Brasileira de Voleibol (2014). Regras Oficiais do Vôlei de Praia 2015-2016. Tradução. Official Beach Volleyball Rules 2015-2016 FIVB - www.fivb.org Approved by The $34^{\circ}$ FIVB 
Congress 2014. Retirado em fevereiro, 14, 2017. http://2017.cbv.com.br/pdf/regulamento/praia/ REGRAS_VOLEI_DE_PRAIA_2015-2016.pdf.

Costa, M. M. (2005). Vôlei de praia : configurações sociais de um esporte-espetáculo de alto rendimento no Brasil. 169 f. Tese (Doutorado em Sociologia) - Universidade de Brasília, Brasília. https://doi.org/ 10.1590/s0102-69922005000300012

Costa, M. M. (2007). Esporte de alto rendimento : produção social da modernidade - o caso do vôlei de praia. Soc Estado, 22(1), 35-69. Retirado em fevereiro, 14, 2017. http:// www.periodicos.unb.br/index.php/estado/article/view/3538/3096. https://doi.org/10.1590/ S0102-69922007000100003

Dias, C. (2008). Por um programa investigativo para os esportes na natureza. Licere, v.11, n.1, 1 -23. Belo Horizonte. Retirado em fevereiro, 14, 2017. https://seer.ufmg.br/index.php/licere/ article/view/645.

Durrive, L. (2011). A atividade humana, simultaneamente intelectual e vital : esclarecimentos complementares de Pierre Pastré e Yves Schwartz. Trab. educ. saúde, 47-67. Retirado em fevereiro, 14, 2017. http://www.scielo.br/pdf/tes/v9s1/03.pdf. https://doi.org/10.1590/

S1981-77462011000400003

Figueiredo, M. G., \& Athayde, M. (2005). Organização do trabalho, subjetividade e confiabilidade na atividade de mergulho profundo. Revista Produção, 15(2), 172-183. Retirado em fevereiro, 14, 2017. http://www.scielo.br/pdf/prod/v15n2/v15n2a03. https://doi.org/10.1590/ s0103-65132005000200004

Schwartz, Y. (1998). Os ingredientes da competência : um exercício necessário para uma questão insolúvel. Educação \& Sociedade, 19(65), 101-140. Retirado em fevereiro, 14, 2017. https:// dx.doi.org/10.1590/S0101-73301998000400004.

Durrive, L., \& Schwartz, Y. (2007/2010). Trabalho e ergologia : conversas sobre a atividade humana. Niterói : EdUFF.

Schwartz, Y. (2014). Motivações do conceito de corpo-si : corpo-si, atividade, experiência. Letras de Hoje, 49(3), 259 - 274. Retirado em fevereiro, 14, 2017. http://revistaseletronicas.pucrs.br/ojs/ index.php/fale/article/view/19102/0. https://doi.org/10.15448/1984-7726.2014.3.19102

Schwartz, Y. (2015). Conhecer e estudar o trabalho. Trabalho \& Educação, v.24, n.3, set-dez, 83-89. Retirado em fevereiro, 14, 2017. http://www.portal.fae.ufmg.br/revistas/index.php/trabedu/ article/view/2340/1631.

\section{NOTAS}

1. Quando falamos de esporte de alto rendimento, apontamos aqui não só para uma profissionalização da prática esportiva, mas também para a criação e o desenvolvimento de tecnologias de movimentos, de divulgação (mídia especializada) e consumos desse esporte (vestimentas, componentes nutricionais, artigos esportivos, etc.).

2. O saque é o fundamento que coloca a bola em jogo, onde o jogador deve lançá-la sobre uma rede - que divide a quadra em dois espaços iguais - em direção ao espaço da dupla adversária; a recepção é um dos fundamentos de defesa, e é utilizada quando a equipe recebe a bola da dupla adversária (após o saque ou um ataque), evitando que a bola toque na areia da quadra interna; o levantamento é um fundamento de passe que geralmente é utilizado quando um dos jogadores da dupla levanta a bola de modo a prepará-la para o parceiro devolvê-la ao campo adversário; o ataque ou virada de bola é a devolução da bola para a quadra adversária na tentativa de marcar o 
ponto; e o bloqueio é outro fundamento de defesa, e acontece quando um dos atletas da dupla realiza um salto próximo à rede de modo a evitar que o adversário devolva a bola sobre a rede e complete o ataque.

3. Cada atleta pode dar apenas um toque na bola; desse modo, para que a dupla consiga lançar a bola para a quadra adversária na tentativa de obter a pontuação, ela deve realizar uma jogada que tenha 3 toques no total. Caso a dupla ultrapasse o número de 3 toques, o ponto é dado à dupla adversária.

4. Palavra utilizada por uma das atletas entrevistadas.

5. Quando utilizamos a expressão Clínicas do Trabalho, falamos da clínica enquanto uma ação onde o sujeito dobrase sobre si mesmo. Neste sentido, uma clínica do trabalho visa à ação sobre um campo profissional e busca desenvolver o "poder de agir" (Clot, 2007; 2010) dos trabalhadores sobre eles mesmos e sobre este campo profissional, operando desvios e construção de outros modos de trabalhar.

6. De acordo com as Regras Oficiais de Vôlei de Praia para os anos de 2013 a 2016, os comportamentos permitidos, caracterizados como "fair play", apontam que "os participantes devem comportar-se de maneira respeitosa não somente para com os árbitros, mas também em relação aos outros oficiais, aos adversários, aos companheiros de equipe e aos espectadores" (Confederação Brasileira de Voleibol, 2014, p.29). Embora não fique claro o que seja uma maneira "respeitosa", o regulamento aponta para 3 condutas passíveis de punição: conduta rude, que seriam condutas contra os "princípios morais e dos bons costumes"; conduta ofensiva, que seriam gestos ou palavras insultantes ou difamantes; e a agressão física a companheiros de time, adversários e arbitragem.

\section{RESUMOS}

Pensar a dimensão coletiva no esporte apenas como divisão de funções entre os atletas dentro de uma equipe pode esconder todos os debates e dramáticas vividos nesta atividade de trabalho. Deste modo, neste artigo, pretendemos analisar como atletas autônomos de vôlei de praia gerenciam suas vidas profissionais na busca de parceiros para formar uma dupla em que seja possível 'jogar junto', mesmo quando a organização do trabalho neste esporte é extremamente competitiva e exige uma alta rotatividade entre seus componentes. A partir das contribuições da Ergologia, da Ergonomia da Atividade e da Clínica da Atividade, pressupomos que para um atleta formar uma dupla, montar um 'time', é necessário que eles coloquem em sinergia suas competências esportivas e, principalmente, tenham condições de construir referenciais cognitivos e valores comuns que possibilitem a comunicação e cooperação no desenvolvimento do trabalho.

Pensar la dimensión colectiva en el deporte solamente como un reparto de funciones entre los deportistas, dentro de un equipo, puede limitar u ocultar todos los debates y molestias experimentados en esta actividad de trabajo. De este modo, en el presente artículo pretendemos investigar como atletas autónomos de voleibol de playa gestionan sus vidas profesionales en la búsqueda de compañeros para constituir una pareja adecuada para el partido conjunto, incluso cuando la organización del trabajo en este deporte es demasiado competitiva y, además, requiere una alta rotación entre sus miembros. A partir de las contribuciones de la Ergología, la Ergonomía y la Clínica de la Actividad, suponemos que para formar una pareja, constituir un 
'equipo', un atleta tiene que poner en sinergia sus competencias deportivas y, sobre todo, poder elaborar referencias cognitivas y valores comunes que le faciliten la comunicación y la cooperación en el desarrollo del trabajo.

Considérer la dimension collective dans le sport en évoquant uniquement la division des fonctions entre les athlètes au sein d'une équipe, pourrait masquer tous les débats et les drames vécus dans cette activité de travail. Ainsi, cet article analyse comment les athlètes autonomes du volleyball de plage gèrent leur vie professionnelle à la recherche de partenaires qui permettent de former une paire pour 'jouer ensemble', même si l'organisation du travail dans ce sport est extrêmement compétitive et si elle exige un renouvellement constant de ses éléments. À partir des contributions de l'Ergologie, de l'Ergonomie de l'Activité et de la Clinique de l'Activité, nous émettons l'hypothèse que, pour former une paire, une 'équipe', un athlète doit mettre ses compétences sportives en synergie et, surtout, il doit être en mesure de pouvoir construire des références cognitives et des valeurs partagées qui lui facilitent la communication et la coopération dans le développement du travail.

Thinking on the collective dimension of sports as a division of functions among athletes within a team may limit and conceal all the existing debates and dramas in such work activity. Thus, the aim of the present study is to assess how autonomous beach volleyball athletes manage their professional lives in the search for partners to form a pair who fits for 'playing together', although the work organisation in the aforementioned modality is extremely competitive and requires high turnover of its members. Based on Ergology, Ergonomics and Clinic Activity, we assume that athletes are required to put their sportive competences in synergy to form a pair, or to set up a team. Besides, above all, we expected these athletes to be able to build cognitive references, as well as common values, which enable communication and cooperation within work development.

\section{ÍNDICE}

Mots-clés: la dimension collective du travail, le travail de l'athlète, la psychologie du travail et du sport, l'ergonomie et le sport, volleyball de plage

Palavras-chave: dimensão coletiva do trabalho, trabalho do atleta, psicologia do trabalho e esporte, ergonomia e esporte, vôlei de praia

Keywords: collective dimension of work, athlete's work, work and sport psychology, ergonomics and sport, beach volleyball

Palabras claves: dimensión colectiva del trabajo, trabajo del atleta, psicología del trabajo y deporte, ergonomía y deporte, voleibol de playa

\section{AUTORES}

\section{LOUISE BORBA}

Grupo de Pesquisas Gestão Trabalho e Atividade - GESTA

Psicóloga da Universidade Federal Fluminense, UFF

Rua Professor Miguel Couto 376, apto 403- Icaraí, Niterói, RJ. CEP : 24230-240, Brasil

louiseborba@id.uff.br 


\section{HÉLDER PORDEUS MUNIZ}

Grupo de Pesquisas Gestão Trabalho e Atividade - GESTA

Professor do Departamento e da Pós-graduação em Psicologia da Universidade Federal

Fluminense, UFF, Rua das Laranjeiras, 347, apto. 607. Laranjeiras, Rio de Janeiro, RJ, CEP

22240-004, Brasil

heldermuniz@uol.com.br 